\title{
Investigation of Tungsten Coatings on Graphite and CFC
}

\author{
R.Neu ${ }^{1}$, H. Maier ${ }^{1}$, E. Gauthier ${ }^{2}$, H. Greuner ${ }^{1}$, T. Hirai ${ }^{3}$, Ch. Hopf ${ }^{1}$, \\ J. Likonen ${ }^{4}$, G. Maddaluno ${ }^{5}$, G. F. Matthews ${ }^{6}$, R. Mitteau ${ }^{2}$, V. Philipps ${ }^{3}$, \\ G. Piazza ${ }^{7}$, C. Ruset $^{8}$, JET EFDA contributors $\ddagger$
}

${ }^{1}$ Max-Planck-Institut für Plasmaphysik, Euratom Association, Garching, Germany

${ }^{2}$ Association Euratom-CEA, Cadarache, DSM/DRFC, Saint Paul Lez Durance, France

${ }^{3}$ Forschungszentrum Jülich, Euratom Association, Jülich, Germany

${ }^{4}$ Association Euratom-TEKES, VTT, Finland

${ }^{5}$ Association Euratom-ENEA, Frascati, Italy

${ }^{6}$ Association Euratom-UKAEA, Culham Science Centre, Abingdon, UK

${ }^{7}$ EFDA-Close Support Unit, Culham Science Centre, Abingdon, UK

${ }^{8}$ National Insitute for Laser, Plasma and Radiation Physics, Association Euratom-MEdC, Bucharest, Romania

\$ See the Appendix of M.L. Watkins et al., Fusion Energy 2006 (Proc. 21st Int. Conf. Chengdu, 2006) IAEA, (2006) 


\begin{abstract}
.
In the frame of JETs ITER-like Wall (ILW) Project tungsten coatings on carbon fibre reinforced carbon substrates will be used in the divertor and highly loaded areas in the main chamber. Fourteen different types of samples were produced by physical or chemical vapour deposition and vacuum plasma spray (VPS) with coating thickness of 4, 10 and $200 \mu \mathrm{m}$. Similarly, three different VPS W coatings ( $200 \mu \mathrm{m})$ on two different graphite substrates, were produced for use at the strike-point regions of ASDEX Upgrade. All coatings were subjected to thermal screening and thermal cycling tests in the ion beam facility GLADIS. Additionally, the coatings intended for the ILW project were exposed to ELM-like thermal loads in the electron beam facility JUDITH. A general failure mode with the CFC substrate is crack formation upon cool-down, whereas the coatings on graphite do not show any crack formation. Aditionally, metallographic investigations, X-ray diffraction measurements, adhesion testing as well as measurements on the contents of light impurities were performed.
\end{abstract}

PACS: 52.40.Hf, 68.60.-p, 68.60.Dv, 81.15.-z, 81.40.Np 


\section{Introduction}

The ITER-like Wall Project (ILW) was launched at JET to investigate the current plasmafacing materials (PFM) choice of ITER [1,2]. Therefore, a beryllium main chamber and as a reference objective a fully tungsten-clad divertor including the strike points will be installed in JET in 2009. The present ITER choice of CFC armours at the strike-points can be accomplished in a later modification. Among the scientific objectives of the project are mixed materials effects on the erosion behaviour as well as wall lifetime investigations and studies on the tritium retention and removal. The reference design foresees the use of bulk tungsten components as a horizontal target plate at the location of the outer strike point region of the divertor [3]. Coatings will be used for the rest of the divertor surfaces as well as areas with high power load at the central column in the main chamber. The W-coatings have to be applied to a $2 \mathrm{~d}$-CFC, which is presently used as PFM in JET. This technical boundary condition is given by the very tight schedule of the ILW project. The main problem to overcome with the development of these coatings is the anisotropy and mismatch of the thermal expansion coefficient of CFC with respect to $\mathrm{W}$. To minimize the risk, a variety of coating methods and a selection of coating thicknesses (14 different sample in total) were supplied by five EURATOM Associations. Physical vapour deposition (PVD) as well as chemical vapour deposition (CVD) techniques were applied to deposit coatings with thicknesses in the micrometer range ('thin' coatings). Using CVD and vacuum plasma spraying (VPS), coatings with a thickness of $200 \mu \mathrm{m}$ ('thick' coatings) were manufactured.

In parallel, three different VPS coatings of $200 \mu \mathrm{m}$ W thickness on graphite with matched thermal expansion were produced for use at the strike point position in the divertor of ASDEX Upgrade as a final step to an all $\mathrm{W}$ device [4]. 
Due to the very tight time frame and the restricted resources for the evaluation of the coatings a scheme was set-up for the testing and the selection of the suitable coating technique. In a first step a thermal screening was applied followed by a cyclic loading which was both performed at the hydrogen beam facility GLADIS [5]. The three types of coatings which performed best in these initial tests were exposed to ELM like thermal shocks in the electron beam facility JUDITH [6]. In parallel, the coated tiles were subjected to metallographic investigations (visible microscopy, SEM, cross sections) and analyses of the stress state and the low-Z impurity content [7]. The paper will describe the evaluation of the test programme, compare the performance of coatings on graphite and CFC and present the conclusion in respect to the final choice made for the coatings to be used in the ILW project.

\section{Sample Types}

\subsection{Coatings on graphite}

The ASDEX Upgrade tungsten program has proven that the rather inexpensive solution of tungsten coatings on fine grain graphite is technically feasible and yields the performance needed in a fusion environment $[8,9]$. During the last few years the W surface in ASDEX Upgrade was continually increased, leaving only the strike-point regions and some parts in the main chamber as uncoated graphite tiles [10]. W marker erosion measurements in JET [11] revealed, that the micrometer thick PVD coatings, which are used in the main chamber would be marginal in the divertor. Therefore W VPS coatings on graphite were envisaged to be used similar to the ones employed during the W divertor experiment in ASDEX Upgrade [12]. Since cracks were observed after their use during the campaign 1995/1996 [13], graphite with an adjusted thermal expansion will be used for the new coatings of the strike-point tiles. The 
reference graphite is SGL R6710 with the thermal expansion $\alpha^{R 6710} \approx 5.8 \cdot 10^{-6} \mathrm{~K}^{-1}$ and the thermal conductivity of $\lambda^{R 6710}=100 \mathrm{~W}(\mathrm{mK})^{-1}$. As a back-up the graphite Schunk FP479 was included $\left(\alpha_{x}^{F P 479} \approx 6 \cdot 10^{-6} \mathrm{~K}^{-1}, \lambda^{F P 479}=100 \mathrm{~W}(\mathrm{mK})^{-1}\right)$ in the tests. In comparison, the value of the thermal expansion for bulk tungsten is $\alpha^{W} \approx 4.9 \cdot 10^{-6} \mathrm{~K}^{-1}$ (averaged over the temperature range $T=20-1000^{\circ} \mathrm{C}$, as for the two graphite grades). Both graphite grades were coated with a $200 \mu \mathrm{m}$ W VPS layer with a W/Re PVD sandwich interlayer produced by Plansee AG with two different porosities of the W layer (90\% and $95 \%$ of the W bulk density). The lower density coating should be more resistant to macroscopic cracks, because the stresses can be released within the porosity, whereas the higher density should have a higher thermal conductivity. A third type W-VPS coating $(120 \mu \mathrm{m})$ with a single (30 $\mu \mathrm{m})$ Re-VPS interlayer was produced on the graphite R6710 by Sulzer-Metco AG.

\subsection{Coatings on $C F C$}

All carbon based in-vessel components of JET are produced from CFC. Therefore it was decided at an early stage of the ILW project to produce the $\mathrm{W}$ coatings on the same or a similar CFC, namely the 2d-CFC Dunlop DMS780. For CFC, however, a new test program was necessary because of the thermal expansion mismatch with tungsten. The majority of the samples were machined with the fibre planes perpendicular to the surface corresponding to the orientation for all divertor tiles ('layout I') where the geometry is denoted as follows: The lateral dimensions are given by $x$ and $y$, whereas the $z$ direction is perpendicular to the sample surface. In that way, the $x$-direction is the only one where no fibres are running [7]. The thermal expansion is about $\alpha_{x}^{C F C} \approx 10 \cdot 10^{-6} \mathrm{~K}^{-1}$ in $x$-direction and $\alpha_{y}^{C F C} \approx 0 \mathrm{~K}^{-1}$ in $y$-direction, respectively. In addition, samples were produced with the fibre planes parallel 
to the surface ('layout II'). In this geometry the lateral thermal expansion is isotropic but the thermal conductivity into the bulk is much lower compared to the above described geometry $\left(70 \mathrm{~W}(\mathrm{mK})^{-1}\right.$ instead $230 \mathrm{~W}(\mathrm{mK})^{-1}$, both values taken at room temperature), allowing this solution to be used only at locations with less power flux density.

Coatings from a variety of coating processes and manufacturers were investigated for risk minimisation in the ILW project. In addition, it was agreed that three different coating thicknesses were to be investigated. These can be separated into two groups called 'thick' and 'thin' coatings here. The thick coatings had a target value of $200 \mu \mathrm{m}$ and the thin coatings had two different target values of $4 \mu \mathrm{m}$ and $10 \mu \mathrm{m}$, respectively. The thickness of $4 \mu \mathrm{m}$ was included in the test, because similar coatings were already employed successfully as markers in the JET divertor $[11,14]$. In the mean time it has, however, been found that $4 \mu \mathrm{m}$ thick $\mathrm{W}$ coatings are insufficient at the outer divertor from the point of view of erosion lifetime [11]. Coating research and development was performed by CEA France, ENEA Italy, IPP Garching Germany, MEdC Romania and TEKES Finland, mostly in cooperation with industry. The deposition methods employed were CVD, different types of PVD, as well as VPS. The total number of different coating thickness / deposition method combinations resulted in 14 (see table 1). According to the specific technique rather different microscopic character of the layers was achieved. Whereas the VPS coatings revealed a rather porous cross section, the PVD and the CVD layers are rather dense. Additionally the CVD technique leads to very closed W surface due the deposition out of the gas phase. This is shown in Fig. 1 (bottom) in comparison to a PVD coating (top) were the layer is deposited in line of sight of the W source. 


\section{High heat flux tests}

\subsection{Experimental Conditions}

The high heat flux testing of all coatings was performed in distinct steps: First, all coating types (one sample for each coating) were subjected to a screening test using the hydrogen beam facility GLADIS [5]. The ion beam has a Gaussian type profile for the power density with a $80 \%$ radius of about $40 \mathrm{~mm}$ (depending on the power level). Central power densities ranged from $6 \mathrm{MWm}^{-2}$ to $23.5 \mathrm{MWm}^{-2}$ with surface temperatures exceeding $T_{\text {surf }}=2000^{\circ} \mathrm{C}$ (see Table 1 in [7]). $T_{\text {surf }}$ was deduced from measurements with a two colour pyrometer, a one colour pyrometer and an infrared (IR) camera. Above $T_{\text {surf }}=1700^{\circ} \mathrm{C}$ only the one colour pyrometer and the IR camera could be used. An emissivity $\varepsilon \approx 0.2$ was deduced from the measurements with the two colour pyrometer. The length of the pulses on the graphite samples was shortened in order to account for the lower thermal conductivity of the substrate and to yield similar surface temperatures compared to the CFC samples.

Fig. 2 shows the thermal response of CFC and graphite (R6710) samples coated by 200 $\mu \mathrm{m} \mathrm{W}$ (VPS) to the screening test. The larger increase of surface temperatures of the graphite samples for a shorter pulse duration are consistent with the lower thermal conductivity of the substrate. In this step all coatings on CFC developed cracks due to the stronger contraction of the coating in one direction upon cool-down after the heat pulse (see below) and five out of the coatings on CFC (1 VPS $(200 \mu \mathrm{m}), 2$ CVD $(200 \mu \mathrm{m}, 10 \mu \mathrm{m})$ and 2 PVD $(4 \mu \mathrm{m}, 10 \mu \mathrm{m}))$ showed local melting or delamination. Three of them showed melting only at the highest power level and the failure of the thin coatings seems to be closely related to the inhomogeneous surface of the CFC. In the case of the graphite tiles the high density W VPS (Plansee) on FP479 melted in the beam centre at the highest power level, probably due to an overheating because 
of the lower thermal conductivity of the substrate. As a criterion for a successful passing of the screening, the absence of delamination and melting was adopted, since the cracks in $y$-direction were judged to be not critical (see Sec.3.2).

In the second step, the coatings types, which passed the thermal screening, were exposed to cyclic heat loading at $10 \mathrm{MWm}^{-2}$ for $5 \mathrm{~s}$ ( $3.5 \mathrm{~s}$ in the case of graphite) corresponding to surface temperatures of about $1600^{\circ} \mathrm{C}$ (above $1700^{\circ} \mathrm{C}$ for graphite). After the 200 pulses were applied, a distinct sub-mm-scale delamination pattern was observed on some thin coatings on the CFC due to fatigue. Some of the $200 \mu \mathrm{m}$ coatings failed before finishing of the cyclic loading. In cases were the result was not unambiguous a second sample of the same coating type was tested. Two VPS-type coatings, StG and Plansee produced one undamaged tile each, in both cases, however, one tile developed a failure. In the case of the StG-VPS tile the failure appeared on the flat surface of the tile, which is not naturally a location of stress peaking. The coating was macroscopically molten within a few pulses. In the case of the Plansee VPS, a delamination grew gradually at an unradiused sharp edge. The original tile design provided for edges with a $1 \mathrm{~mm}$ radius and sharp edges. The reason for this was to investigate the influence of these features on the coating adhesion, because edges are known locations of stress peaking. It was anticipated that sharp edges might lead to problems. The existence of this sharp feature had, however, been regarded as critical to start with. Instead, all 4 tested graphite/W-coating survived the test without any failure, although showing cracks on a few micrometer scale due to stress relaxation (the graphite samples only had rounded edges). Fig. 3 shows SEM pictures of the surface of VPS coatings (Plansee, 90\% density) on CFC and graphite (R6710) after cyclic loading. The large crack on the CFC sample (top) is typical for all thick coatings on CFC and is part of the regular crack structure due to the mismatch in 
thermal expansion as described below.

In a final step, selected CFC samples (VPS $200 \mu \mathrm{m}$, Plansee and StG; PVD $10 \mu \mathrm{m}$, MEdC [16]) were exposed to ELM-like heat loads (1000 pulses, $\left.0.35 \mathrm{GWm}^{-2}, 1 \mathrm{~ms}\right)$ at the electron beam facility JUDITH (FZ Jülich) [6]. For this purpose, only areas of the samples with the size $8 \times 8 \mathrm{~mm}^{2}$ were subjected to the scanning e-beam in order to keep the energy input in the sample low and to allow a fast repetition of the pulses. Under these thermal shocks, the thick coatings exhibited a better performance than the thin one, which started to show also the fatigue failure described above. The better performance of the thick coatings in this test could be explained by their higher heat capacity and strength as discussed below.

\subsection{Discussion of results}

In this section we give a tentative and qualitative explanation of the basic stresses occurring in the coatings during a thermal heat pulse and the resulting failure modes. The coordinates we use are explained above: In layout I, the $y$-direction is the direction of the fibres on the surface of the test tiles.

Upon a temperature increase the coating tends to expand more than the substrate in $y$-direction and less than the substrate in $x$-direction. For this reason the coating will experience a tensile stress change $(\Delta \sigma>0)$ in $x$-direction and a compressive stress change $(\Delta \sigma<0)$ in $y$-direction during temperature rise. The PVD coatings investigated here are generally in a state of compressive stress at room temperature in both directions (see Sec. 4.2). While in $x$-direction the magnitude of the compressive stress decreases in a certain temperature interval (which depends on the initial stress state), we obtain an increase of magnitude in $y$-direction, which could lead to problems in principle. Both load modes can, however, obviously be tolerated by the coatings. As soon as the surface temperature reaches values, where stress 
relaxation can occur with sufficient efficiency, i.e. fast enough, the stress state of the films will tend to change towards $\sigma=0$. Mechanisms for this are plastic deformation in general, creep, or re-crystallisation. It is important to mention here, that all of the above mechanisms are thermally activated processes. Therefore the stress relaxation may occur in a single pulse at sufficiently high temperature or it may occur incrementally with increasing pulse number at lower peak temperatures. Starting from an almost stress-free state at high temperature, the cooling process will reverse the above picture and the coatings will be compressed in $x$ direction and experience a tensile load in $y$-direction. Experimentally it was observed that the magnitude of this tensile load in $y$-direction exceeds the tensile strength of the coatings. This leads to cracks in the coating which are oriented perpendicular to the tensile load, i.e. cracks which are parallel to the $x$-axis ('failure mode 1') [7]. These cracks must appear at a certain characteristic spacing, which depends approximately linearly on the coating thickness. For the $200 \mu \mathrm{m}$ coatings, this distance is approximately $4 \mathrm{~mm}$. For the thin coatings this distance is consequently in the range of $100 \mu \mathrm{m}$ (see [7] Fig.2).

In the $x$-direction we end up with a situation as it was initially: Compressive stress. Here the cyclic loading serves as a test for low cycle fatigue phenomena, occurring for components which experience loads beyond the yield condition for $<10^{4}$ loading cycles. In our case delamination occurred for the thin coatings $(4$ and $10 \mu \mathrm{m})$ rather generally (with one exception) within the 200 cycles that were applied during cyclic loading. The effect occurred always on fibre bundles lying parallel to the surface, i.e. in $y$-direction. During cool-down of the sample, this delaminated coating is compressed in $x$-direction, as illustrated in Fig. 4 (top). The $y$-direction, i.e. the direction of the fibres, is perpendicular to the paper surface. The compression results in a buckling-out of coating areas which are unbound or loosely 
bound to the substrate ('failure mode 2'). The compressive force is given by the contraction of the substrate. The resulting compressive stress depends on the thickness of the coating and decreases with increasing coating thickness (larger cross section). Hence the stress of the thinner coatings exceeds that of thicker coatings at otherwise similar conditions. Additionally, thinner coatings show a lower rigidity with respect to the bending forces associated with the buckling effect. Therefore stress relaxation by buckling can already occur at lower stress levels. Since the cyclic loading was performed only at one power level the lateral occurrence of the failure on the samples was investigated in order to get information on its power dependence. Taking into account the Gaussian power density profile of the ion beam one can conclude that even a reduction of the power density down to $5 \mathrm{MW} / 2$ is insufficient to avoid the buckling. Finally, the third failure mode observed is a consequence of the delamination/buckling described above: As we repeatedly heat the sample in cyclic loading, the existing buckles will experience bending forces during each heating/cooling cycle (Fig. 4, bottom). This bending represents a plastic deformation of the coating and therefore leads to cumulative crack formation along the principal bending lines ('failure mode 3'), as shown in [7].

The VPS coatings on CFC (Plansee, StG) passed also the ELM type loading at 0.35 $\mathrm{GWm}^{-2}$ without macroscopic damage, although the metallographic post examination of these CFC samples revealed that the thick coatings had already developed one necessary precondition for failure, namely the local detachment at locations where the fibre bundles run parallel to the surface (see Fig. 5). The adhesion strength there is limited by the weak tensile strength of the matrix material. Therefore the increased stiffness of the thick coatings as compared to the thin coatings was the dominating effect here, which prevented the occurrence 
of buckling.

\section{Further Analyses}

\subsection{Adhesion}

The adhesion of the coatings was tested by gluing a stainless steel cylinder of $1 \mathrm{~cm}$ in diameter to the surface of the coated tile. The cylinder was pulled upward by a tensile testing machine. The interlaminar tensile strength of the Dunlop CFC is 5.2MPa. All 4 and $10 \mu \mathrm{m}$ coatings significantly exceeded 5MPa, some by more than a factor of four. In order to understand these high values it has to be kept in mind that the CFC is a very rough and porous material. The thin coatings do not close the pores and cavities (see Fig.1), hence, the glue for adhesion testing penetrates and fills the pores leading to mechanical interlocking with the fibres of the CFC itself. The maximum values obtained on the thin coatings should therefore not be mistaken as a measure for adhesion of the coating. On the other hand, there is, no indication of adhesion problems with any of these coatings. Unlike the thin coatings, the $200 \mu \mathrm{m}$ layers close the pores and prevent glue from penetrating around fibres. Hence, the measured values do reflect the adhesive strength of the W-C interface. The results for the four thick coatings are very different. The ATL (CVD) and Plansee (VPS) coatings reach very high values of up to 19MPa. These high values are probably also the result of mechanical interlocking, this time between the tungsten coating and the CFC. In contrast, the samples from Centro Sviluppo Materiali and Saint Gobain $(\mathrm{StG})$ reach only tensions of 8 and 6MPa, respectively. The adhesion of the coatings on graphite was only measured for the ones produced by Plansee. The failure during the pulling tests always appeared in the substrate reaching values of 25.2-29.2 MPa for R6710 and 13.0-24.3 MPa for FP479. 


\subsection{Stresses}

All 14 coating types on CFC were analysed with respect to their stress state at room temperature using the so-called $\sin ^{2} \phi$-method. This method determines the in-plane stress by measuring the angle-dependent position of a diffraction peak and extrapolating this value. The analysis was run with an aperture diameter of $2 \mathrm{~mm}$. With respect to their stress states, the analysed coatings clearly separate into groups according to their production method. It is known from literature that the PVD methods employed here produce coatings with a pronounced level of compressive intrinsic stress $\sigma<0[9,15]$. This is clearly reflected in Fig. 6. The MEdC sample produced by magnetron sputtering [16] deserves special attention, since in previous studies [17] the magnitude of compressive stress in magnetronsputtered samples was much higher. Obviously, the periodical high energy ion bombardment (combined magentron sputtering ion implantation) used during the coating process induces a stress relief at the interface and within the layer. The DIARC samples display a distinctly higher magnitude of compressive stress than the other PVD samples. However, the observed negative slope of the angular dependence of the stress level (for two of the samples) cannot be accounted for by the anisotropic thermal expansion mismatch. Both types of thin CVD coatings display a moderate stress level with a direction-dependent change of sign indicating that they grow close to stress-free at the deposition temperature and produce an anisotropic stress level when cooling to room temperature according to the anisotropic thermal expansion mismatch between coating and substrate. All four types of thick coatings display a low magnitude of tensile stress between $40 \mathrm{MPa}$ and $100 \mathrm{MPa}$, which is orientation-independent (not shown in Fig. 6). This reflects only the stress level near the surface of the coatings, since the analysis method averages over a depth in the $\mu \mathrm{m}$ range. Due to this reason no 
measurements were performed for the VPS coatings on the graphite substrates.

\section{Summary and Conclusions}

Tungsten coatings on graphite and CFC substrates have been produced and tested for their applicability in fusion devices. Generally their low-Z impurity content is in the percentage range [7] and the adhesion of the coating is in the range of the strength of the substrate material. The stress states of the thin coatings is lowest for CVD coatings $( \pm 200 \mathrm{MPa}$ depending on orientation relative to the fibres) and reaches values above $800 \mathrm{MPa}$ for the PVD coatings.

In the GLADIS low cycle fatigue tests all thin coatings except for the samples from MEdC developed the fatigue-related failure, namely cracks and buckling. The further development of these failure modes with increasing pulse number is not known, but must be considered as dangerous to the coatings. In addition the reaction of the buckled structures to additional ELM loading must be considered. The reason for the one exception is most likely the presence of an intermediate Mo coating serving as a compliant interlayer [16]. In the ELM-like loading test with 1000 pulses, however, also this coating developed similar failures and coating removal was observed on several spots with lateral dimensions on the order of $100 \mu \mathrm{m}$. Here it must be considered that the total number of 1000 ELM-like loading pulses would be exceeded in JET by two orders of magnitude. For these reasons thin coatings of $4 \mu \mathrm{m}$ and $10 \mu \mathrm{m}$ thickness cannot be recommended for locations with a high cyclic power density, i.e. the strike point area tiles. Investigating the lateral occurrence of the failure and taking into account the Gaussian power profile of the ion beam one can conclude that a reduction of the power density by a factor of 2 is insufficient to avoid the cracking. In case of the thick coatings most 
of the VPS-type coatings on CFC (StG, Plansee) and graphite (Plansee, SM) survived the screening up to $23.5 \mathrm{MWm}^{-2}$ as well the cyclic loading at $10.5 \mathrm{MWm}^{-2}$. The failure modes indicate that higher coating densities (lower porosity) are more prone to failure and that sharp edges of the tiles should be avoided since they could initiate defects. Two VPS coatings on CFC (Plansee, $\mathrm{StG}$ ) passed also the ELM type loading at $0.35 \mathrm{GWm}^{-2}$. Therefore such coatings can be applied in divertor areas of high power density, although the metallographic post examination of these CFC samples revealed that the thick coatings had already developed local detachment. The adhesion strength here is limited by the weak tensile strength of the matrix material. Additionally, this result suggests that the use of coated CFC with the fibre plane parallel to the surface (layout II) should be restricted to areas with low power load, not only due to the reduced thermal conductivity but also because of the limited adhesion. Since the thermal expansion of graphite is much better adapted to tungsten the risk of failure of the coating seems to be lower and graphite should be used as long as the thermal and mechanical load are consistent with its properties. 
[1] J. Pamela, G. Matthews, V. Philipps, and R. Kamendje, An ITER-like wall for JET, in 17th Int. Conf. on Plasma Surface Interaction, Hefei, to be published in J. Nucl. Mater., 2006.

[2] G. Matthews, P. Edwards, T. Hirai, M. Kear, A. Lioure, P. Lomas, A. Loving, C. Lungu, H. Maier, P. Mertens, D. Neilson, R. Neu, J. Pamela, V. Philipps, G. Piazza, V. Riccardo, M. Rubel, C. Ruset, M. Villedieu, E. Way on behalf of the ITER-like Wall Project Team, Material aspects in the ITER-like wall project, in this conference, submitted to Physica Scripta, 2006.

[3] T. Hirai, H. Maier, M. Rubel, P. Mertens, R. Neu, E. Gauthier, J. Likonen, C. Lungu, G. Maddaluno, G. Matthews, R. Mitteau, O. Neubauer, G. Piazza, V. Philipps, B. Riccardi, C. Ruset, I. Uytdenhouwen, and JET EFDA contributors, R\&D on full tungsten divertor and beryllium wall for JET ITER-like Wall Project, in 24. Symp. of fusion technology, Warschau, submitted to Fusion Eng. Design, 2006.

[4] R. Neu, V. Bobkov, R. Dux, A. Kallenbach, T. Pütterich, H. Greuner, O. Gruber, A. Herrmann, C. Hopf, K. Krieger, C.F. Maggi, H. Maier, M. Mayer, K. Schmid, W. Suttrop, V. Rohde, and ASDEX Upgrade team, Final steps to an all tungsten divertor tokamak, in 17th Int. Conf. on Plasma Surface Interaction, Hefei, to be published in J. Nucl. Mater., 2006.

[5] H. Greuner, B. Böswirth, J. Boscary, and N. Rust, High heat flux facility GLADIS - Operational Characteristics and Results of W7-X Pre-Series Target Tests, in 12th Int. Conf. on Fusion Reactor Materials, Santa Barbara, to be published in J. Nucl. Mater., 2006.

[6] R. Duwe, W. Khnlein, and H. Münstermann, in Proc. 18th SOFT, Karlsruhe, Germany, page 335, Fusion Technology, 1994.

[7] H. Maier, R. Neu, H. Greuner, C. Hopf, G.F. Matthews, G. Piazza, T. Hirai, G. Counsell, X. Courtois, R. Mitteau, E. Gauthier, J. Likonen, G. Maddaluno, V. Philipps, B. Riccardi, and C. Ruset, Tungsten Coatings for the JET ITER-like wall project, in 17th Int. Conf. on Plasma Surface Interaction, Hefei, to be published in J. Nucl. Mater., 2006.

[8] C. García-Rosales, S. Deschka, W. Hohenauer, R. Duwe, E. Gauthier, J. Linke, M. Lochter, W.K.W.M. Malléner, L. Plöchl, P. Rödhammer, A. Salito, and ASDEX Upgrade Team, Fusion Tech. 32, 263-276 (1997).

[9] H. Maier, Materials Science Forum 475-479, 1377-1382 (2005).

[10] R. Neu, R. Dux, A. Kallenbach, T. Pütterich, M. Balden, J. C. Fuchs, A. Herrmann, C. F. Maggi, M. O’Mullane, R. Pugno, I. Radivojevic, V. Rohde, A. C. C. Sips, W. Suttrop, A. Whiteford, and ASDEX 
Upgrade Team, Nucl. Fusion 45(3), 209-218 (2005).

[11] M. Mayer, J. Likonen, J. Coad, H. Maier, M. Balden, S. Lindig, E. Vainonen-Ahlgren, V. Philipps, and JET EFDA contributor, Tungsten erosion in the outer divertor of JET, in 17th Int. Conf. on Plasma Surface Interaction, Hefei, to be published in J. Nucl. Mater., 2006.

[12] R. Neu, K. Asmussen, S. Deschka, A. Thoma, M. Bessenrodt-Weberpals, R. Dux, W. Engelhardt, J. C. Fuchs, J. Gafert, C. García-Rosales, A. Herrmann, K. Krieger, F. Mast, J. Roth, V. Rohde, M. Weinlich, U. Wenzel, ASDEX Upgrade Team, and ASDEX NI Team, J. Nucl. Mater. 241-243, 678-683 (1997).

[13] H. Maier, S. Kötterl, K. Krieger, R. Neu, M. Balden, and ASDEX Upgrade Team, J. Nucl. Mater. 258-263, 921-926 (1998).

[14] S. Lehto, J. Likonen, J. Coad, T. Ahlgren, D. Hole, M. Mayer, H. Maier, and J. Kolehmainen, Fusion Eng. Design 66-68, 241 (2003).

[15] J.A. Thornton and D.W. Hoffmann, Thin Solid Films 171, 5-31 (1989).

[16] C. Ruset, E. Grigore, H. Maier, R. Neu, X. Li, H. Dong, R. Mitteau, and X. Courtois, W coatings deposited on CFC tiles by combined magnetron sputtering and ion implantation technique, in this conference, submitted to Physica Scripta, 2006.

[17] H. Maier, J. Luthin, M. Balden, M. Rehm, F. Koch, and H. Bolt, Surface and Coatings Technology 142144, 733-737 (2001). 


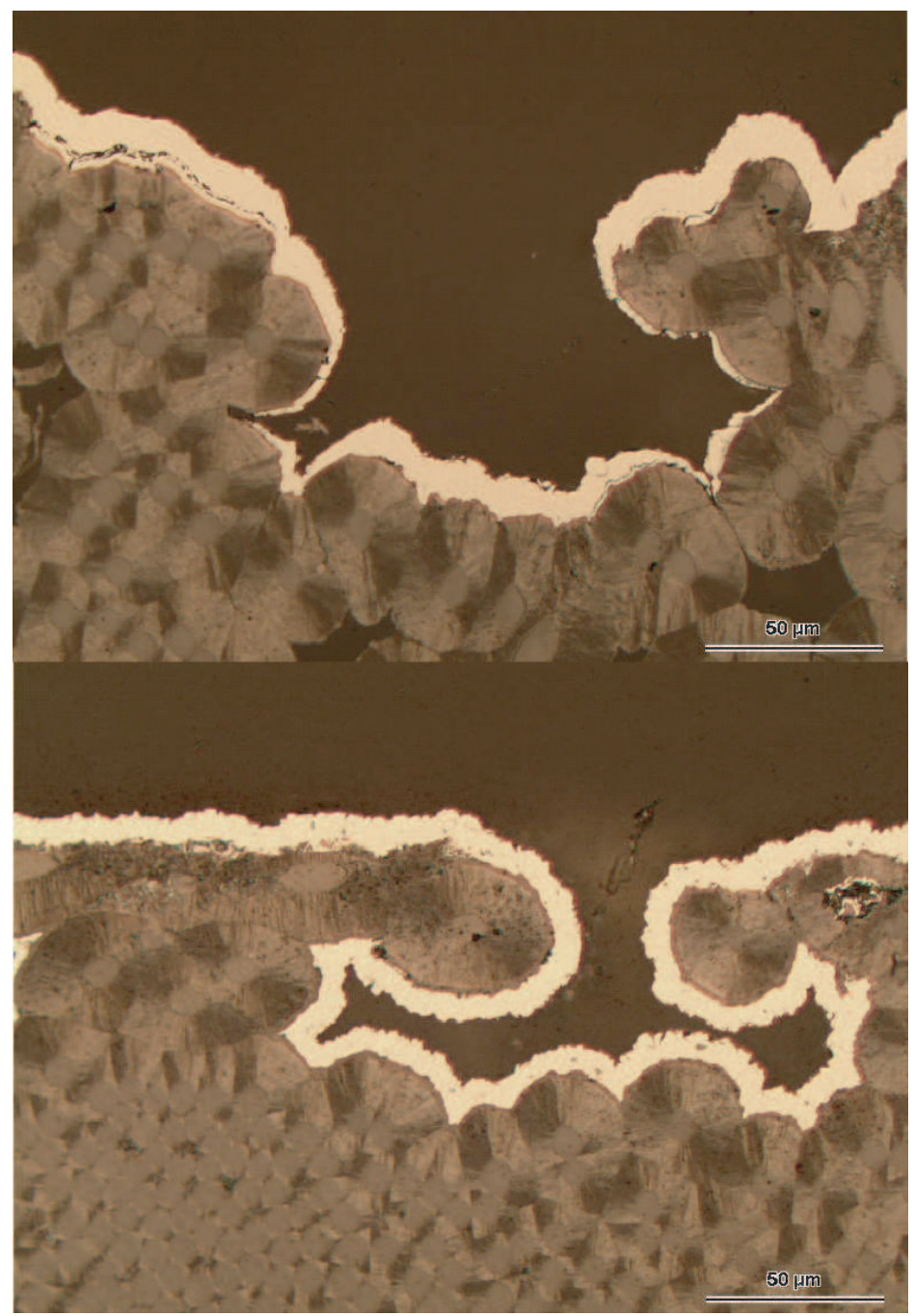

Figure 1. Cross sections of tiles with CFC substrate with coatings of $10 \mu \mathrm{m}$ thickness produced by PVD (top, Plansee AG) and CVD (bottom, Archer Technicoat Ltd. (ATL)) 


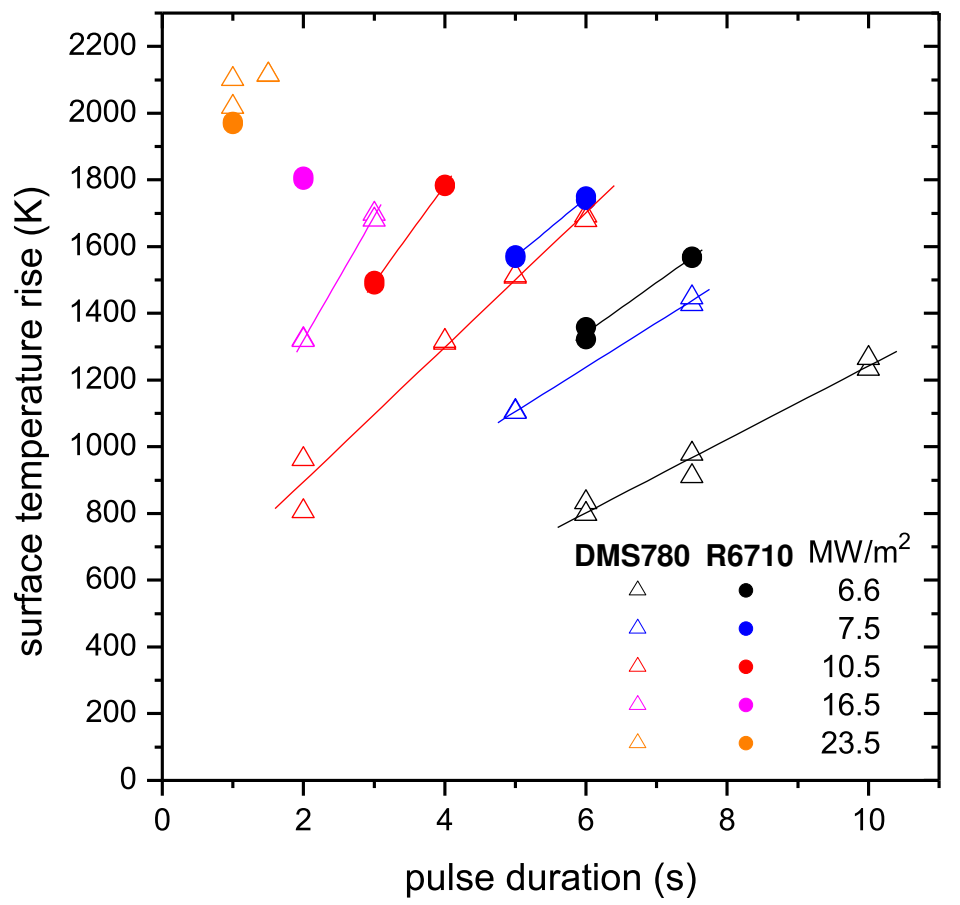

Figure 2. Thermal response of Dunlop DMS780 2d CFC (dots) and SGL R6710 graphite (triangles) samples coated by $200 \mu \mathrm{m} \mathrm{W}$ (VPS) to the screening test with power loads indicated in the figure. The larger increase of surface temperatures of the graphite samples for a shorter pulse duration are consistent with the lower thermal conductivity of the substrate. The lines indicate only the cycles with the same power load. 


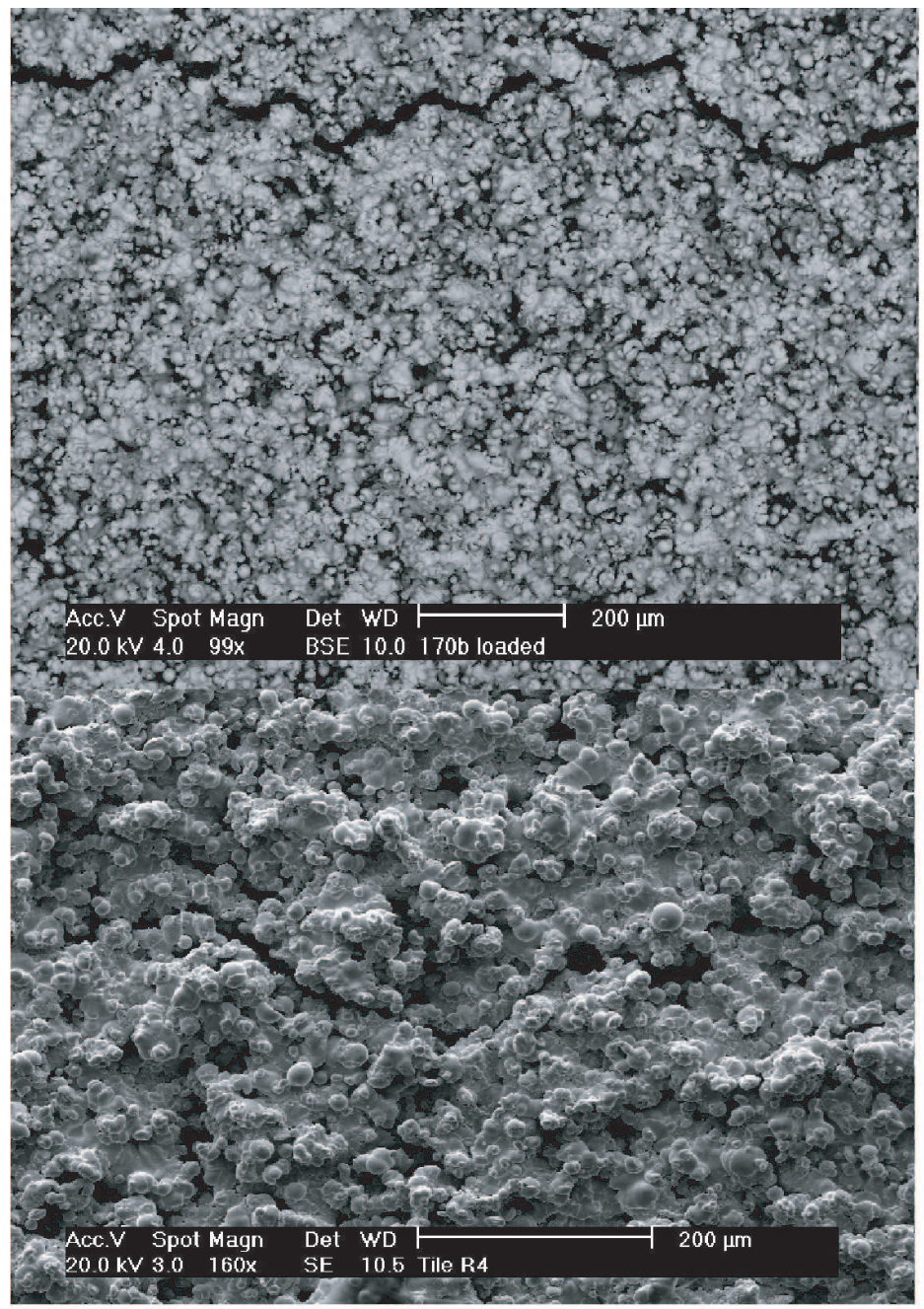

Figure 3. SEM pictures of VPS coatings (Plansee, 90\% density) on CFC (top) and graphite (bottom) after cyclic loading. Please note the slightly different magnification. 


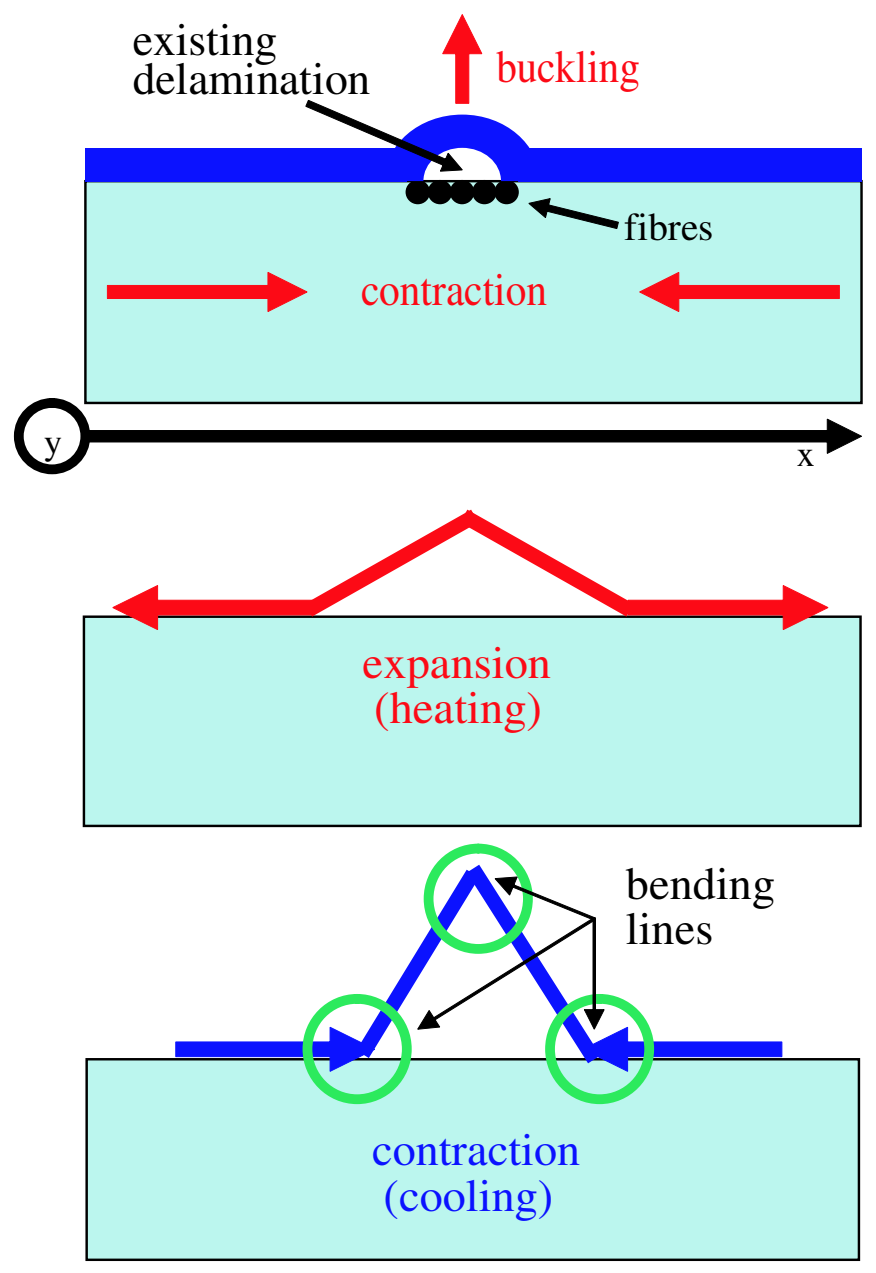

Figure 4. Sketch of the conditions leading to buckling of the W coatings on CFC (top) and the repeated plastic deformation leading to cracking. 


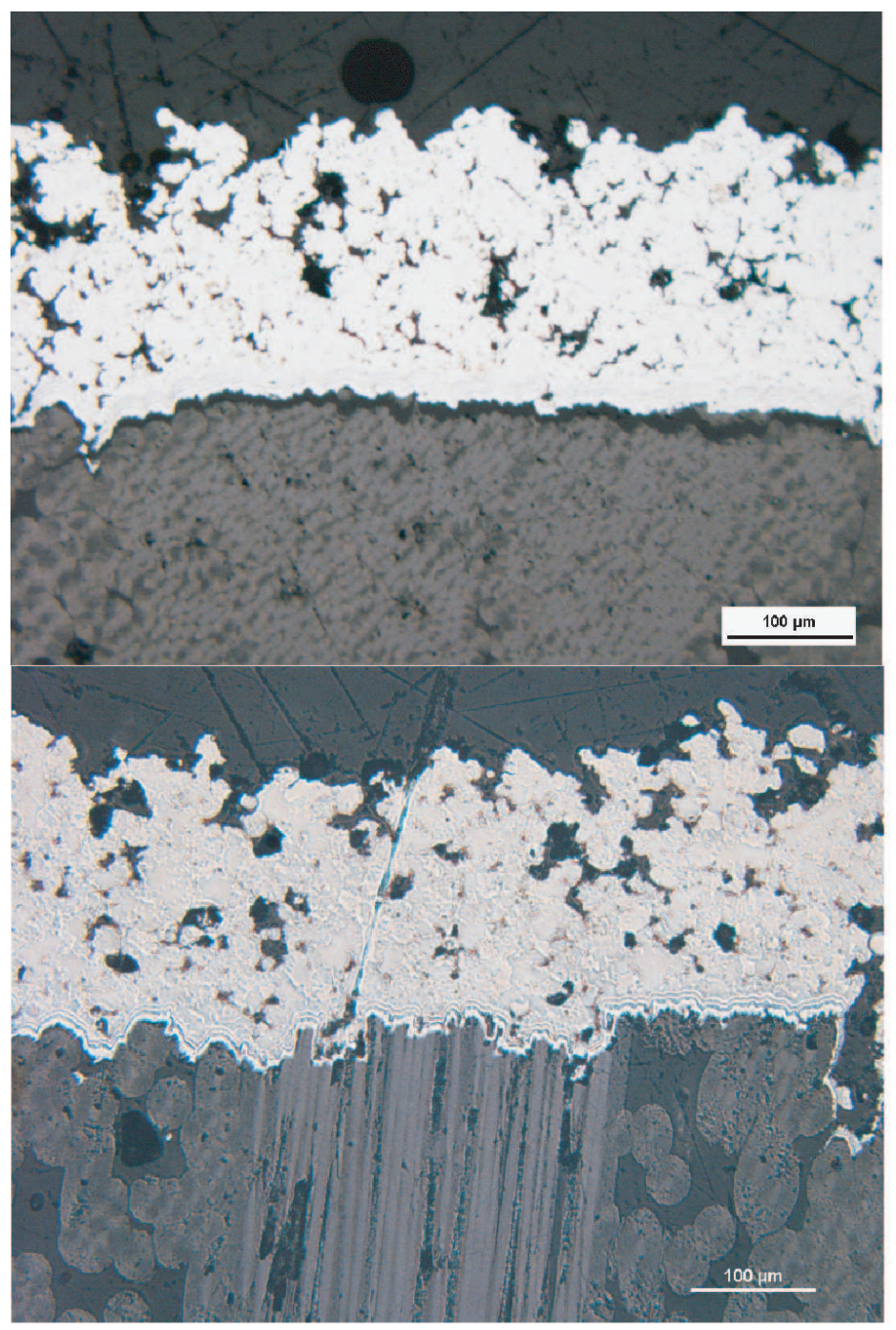

Figure 5. Optical micrographs of metallographic cross sections of the VPS coating (Plansee) on CFC at locations with fibres parallel (top) and perpendicular (bottom) to the layer boundary after the ELM-like thermal shock tests. 


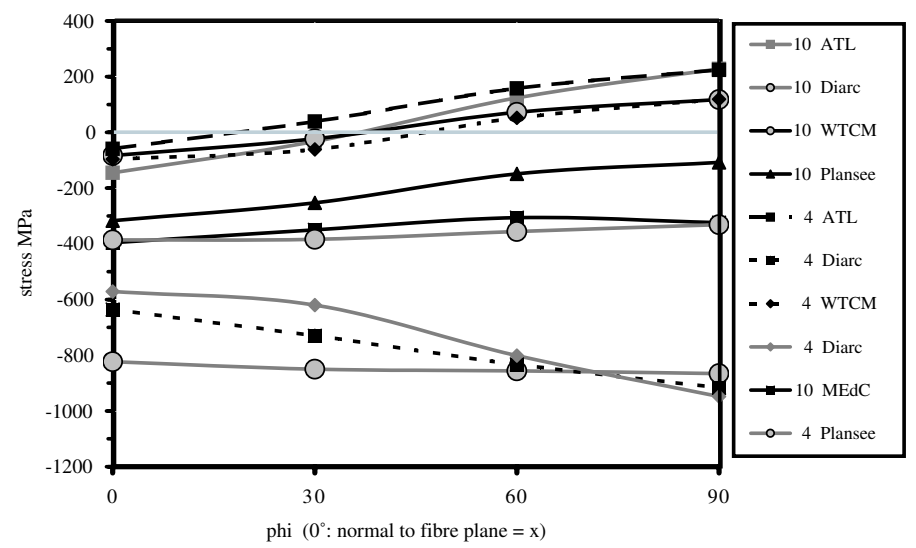

Figure 6. Stress states of the thin coatings at room temperature as measured by X-ray diffraction. Values of bulk tungsten used for evaluation. (The numbers in the legend give the coating thickness in $\mu \mathrm{m}$. 


\begin{tabular}{|c|c|c|c|}
\hline Supplier & Technique & Interlayer & Thickness $(\mu \mathrm{m})$ \\
\hline \multicolumn{4}{|l|}{ Coatings on $\mathrm{CFC}$} \\
\hline Plansee AG, A & PVD & - & $2-6$ \\
\hline DIARC Techn., FIN & PVD & - & $3-5$ \\
\hline DIARC Techn., FIN & PVD & $\operatorname{Re}$ & $5-7$ \\
\hline Archer Techn. Ltd., GB (ATL) & CVD & - & $7-8$ \\
\hline WTCM, B & CVD & - & 4 \\
\hline Plansee AG, A & PVD & - & $11-13$ \\
\hline DIARC Techn., FIN & PVD & - & $8-14$ \\
\hline MEdC, RO & PVD & Mo (II) & $10-13$ \\
\hline Archer Techn.Ltd., GB (ATL) & CVD & - & $12-14$ \\
\hline WTCM, B & CVD & - & $4-10$ \\
\hline Centro Sviluppo Materiali, I & VPS & $\mathrm{TiC}$ & $230-250$ \\
\hline Plansee, A & VPS & $\mathrm{W} / \mathrm{RE}(\mathrm{SW})$ & $220-240$ \\
\hline St.Gobain, F (StG) & VPS & $\operatorname{Re}$ & $190-260$ \\
\hline Archer Techn.Ltd., GB (ATL) & CVD & $\operatorname{Re}$ & $240-250$ \\
\hline \multicolumn{4}{|l|}{ Coatings on Graphite } \\
\hline Plansee AG, A & VPS & W/RE (SW) & $220-240$ \\
\hline Sulzer-Metco AG, CH (SM) & VPS & $\operatorname{Re}$ & 150 \\
\hline
\end{tabular}

Table 1. Supplier, coating technique, interlayer (SW: sandwich layers, II: ion implantation) and thicknesses as assessed from metallographic cross-sections 